\title{
Regulation of Skeletal Muscle Stem Cell Behavior by Pax3 and Pax 7
}

\author{
M. Lagha, ${ }^{*}$ T. SATO, ${ }^{*}$ L. Bajard ${ }^{\ddagger}$ P. Daubas, ${ }^{*}$ M. Esner, ${ }^{\ddagger}$ \\ D. Montarras, ${ }^{*}$ F. Relaix ${ }^{\dagger}$ and M. BuCKinghaM* \\ *Department of Developmental Biology, CNRS URA2578, Pasteur Institute, 75015 Paris, France
}

\begin{abstract}
Pax genes have important roles in the regulation of stem cell behavior, leading to tissue differentiation. In the case of skeletal muscle, Pax 3 and $\operatorname{Pax} 7$ perform this function both during development and on regeneration in the adult. The myogenic determination gene Myf5 is directly activated by Pax3, leading to the formation of skeletal muscle. Fgfr 4 is also a direct Pax3 target and Sprouty 1 , which encodes an intracellular inhibitor of fibroblast growth factor (FGF) signaling, is under Pax 3 control. Orchestration of FGF signaling, through Fgfr 4/Sproutyl, modulates the entry of cells into the myogenic program, thus controling the balance between stem cell self-renewal and tissue differentiation. This and other aspects of Pax3/7 function in regulating the behavior of skeletal muscle stem cells are discussed.
\end{abstract}

The entry of stem cells into the skeletal muscle program is characterized by the activation of genes of the $M y o D$ family, which encode myogenic regulatory factors essential for the commitment to this cell fate, controling myogenic determination and subsequent differentiation (Fig. 1). However, more recently, it has become clear that members of the Pax gene family, $\operatorname{Pax} 3$ and $\operatorname{Pax} 7$, lie upstream of these myogenic genes and that their expression marks the skeletal muscle stem cell. In this context, we present the cell populations that contribute to myogenesis in the mouse embryo and in the perinatal period during muscle growth and later regeneration.

Pax genes have important roles in tissue specification and organogenesis during development (Fig. 2). A classic example is provided by Pax 6 required for the formation of the eye, a function conserved from Drosophila to humans. Other cell types that depend on Pax genes include the Blymphocyte lineage that depends on Pax 5 or the endocrine cells of the pancreas that depend on Pax4 and Pax6. Many facets of Pax function have emerged from the different cell

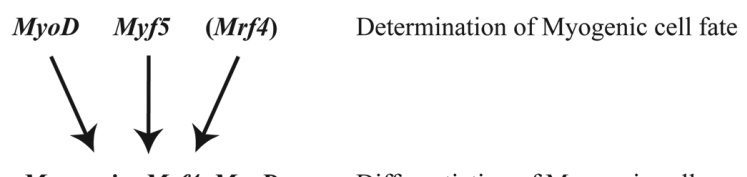

Myogenin, Mrf4, MyoD Differentiation of Myogenic cells

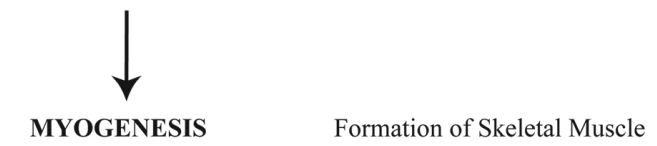

Figure 1. Myogenic regulatory factors. The functions of these skeletal-muscle-specific basic helix-loop-helix transcription factors have been determined by gene mutation in the mouse.

Present addresses: ${ }^{\dagger}$ Mouse Molecular Genetics group, UMR S787, Groupe Myologie, INSERM-UPMC-Paris VI, Faculté de Médecine Pitié-Salpétrière, 105 bd de l'Hôpital, 75634, Paris Cedex 13, France; ${ }^{*}$ Max-Planck Institute of Molecular Cell Biology and Genetics, Pfotenhauerstr. 108, 01307 Dresden, Germany. systems in which they have been studied, notably maintenance of a multipotent state, direction into a differentiation program, cell migration, proliferation, and survival (see Buckingham and Relaix 2007). In skeletal muscle stem cells, Pax 3 and Pax 7 appear to be implicated in these various aspects of cell behavior. Identification of Pax3/7 targets is now beginning to clarify the role of these key regulators. Here, this is discussed mainly with reference to skeletal muscle stem cells during development, with an emphasis on the function of Pax3/7 in modulating stem cell renewal versus entry into the myogenic program.

\section{THE CELLS THAT FORM SKELETAL MUSCLE}

To understand the stem cells of adult tissues, and indeed to learn how to manipulate them for therapeutic purposes, it is important to know their embryological origin and how such cells contribute to the formation of the tissue during development (Buckingham and Montarras 2008).

\section{Myogenesis in the Embryo}

Skeletal muscles in the trunk and limbs are derived from paraxial mesoderm and from cells present in the dorsal compartment of the somite, an epithelial structure known as the dermomyotome (Fig. 3a). These cells express $\mathrm{Pax} 3 / 7$. At the onset of myogenesis in the mouse embryo, the linked myogenic determination genes Myf5 and Mrf4 are activated, without direct intervention of the Pax factors. Canonical Wnt (Borello et al. 2006) and Sonic Hedgehog (Shh) (Borycki et al. 1999; Gustafsson et al. 2002; Teboul et al. 2003) signaling, from the axial structures of the adjacent neural tube and notochord, directly regulate an early epaxial Myf5 enhancer element, in cells at the epaxial (closest to the axis) edge of the dermomyotome. At later stages, $M y o D$ is also activated independently in this domain by signals from the neural tube and notochord (Tajbakhsh et al. 1998). Activation of myogenic 


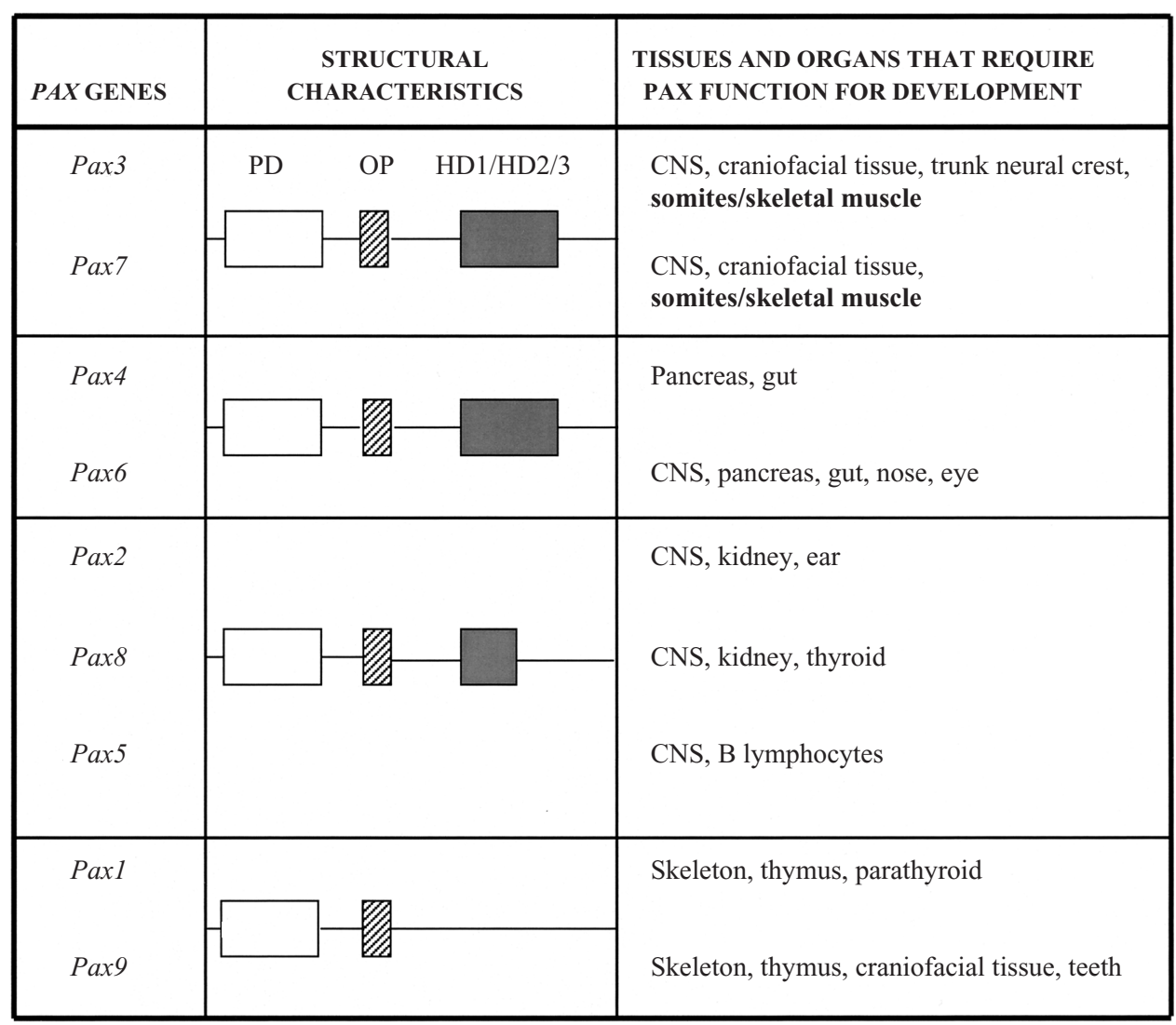

Figure 2. The Pax family of regulatory factors.

determination genes by axial signals leads to the formation of the early myotome, a differentiated muscle mass located underneath the dermomyotome. However, the activation of Myf5 later in the hypaxial (furthest from the axis) dermomyotome depends on Pax3 (Bajard et al. 2006), and Pax 3 transcriptional activity, which also controls $M y o D$, is regulated by noncanonical Wnt signaling from the overlying dorsal ectoderm, acting through a protein kinase $\mathrm{C}$ (PKC)-dependent pathway (Brunelli et al. 2007). Pax3 functions as a transcriptional activator in the myogenic context in vivo (Relaix et al. 2003), but it is not very effective on its own and probably requires cofactors and/or protein modifications such as phosphorylation, which may be affected by the PKC pathway. Pax3-positive cells that form the early myotome delaminate from the edges of the dermomyotomal epithelium as Myf5/Mrf4-positive cells and rapidly differentiate. Other cells delaminate and migrate from the somite to more distant sites of myogenesis, such as those in the limbs, before activating the myogenic regulatory factor genes (Fig. 3b). This process is Pax3-dependent, through direct regulation of c-met (see Buckingham and Relaix 2007).

Subsequent myogenesis in the trunk depends on Pax3/7. After the initial Myf5/Mrf4-dependent wave of myogenesis in the somite, the epithelial structure of the dermomyotome begins to disaggregate and Pax3/7-positive cells from the central dermomyotome are parachuted into the underlying myotomal muscle (Fig. 3c). These cells provide a source of myogenic progenitors for all sub- sequent muscle growth. They are a proliferative population that either self-renews or moves into the myogenic program with activation of Myf5 and MyoD. Cells that express these myogenic determination factors undergo limited proliferation, as a transit-amplifying population, but then differentiate into skeletal muscle. It is therefore the upstream Pax-positive cells, in both the trunk and the limbs, that constitute a self-renewing muscle stem cell population. In double $P a x 3 / 7$ mutant embryos, the early myotome forms, but subsequent muscle development is compromised (Relaix et al. 2005).

\section{The Muscle Satellite Cell}

Pax-positive cells are initially intermingled with muscle fibers in the growing muscle masses. However, by late fetal stages, a basal lamina begins to be laid down and Pax3/7-positive cells are now found adjacent to the muscle fiber under the basal lamina. This is the characteristic position of the satellite cell, a quiescent cell that when activated contributes to postnatal muscle growth and to muscle regeneration (Montarras and Buckingham 2008). Satellite cells are marked by the expression of Pax7, and in many, but not all, muscles, $\operatorname{Pax} 3$ is also transcribed in these cells (Relaix et al. 2006). Satellite cells are heterogeneous, also, in that many of them already transcribe Myf5 (Beauchamp et al. 2000), and indeed most of them have done so at some stage in their history (Kuang et al. 2007), unlike the proliferating $P a x 3 / 7$ cells of prenatal develop- 

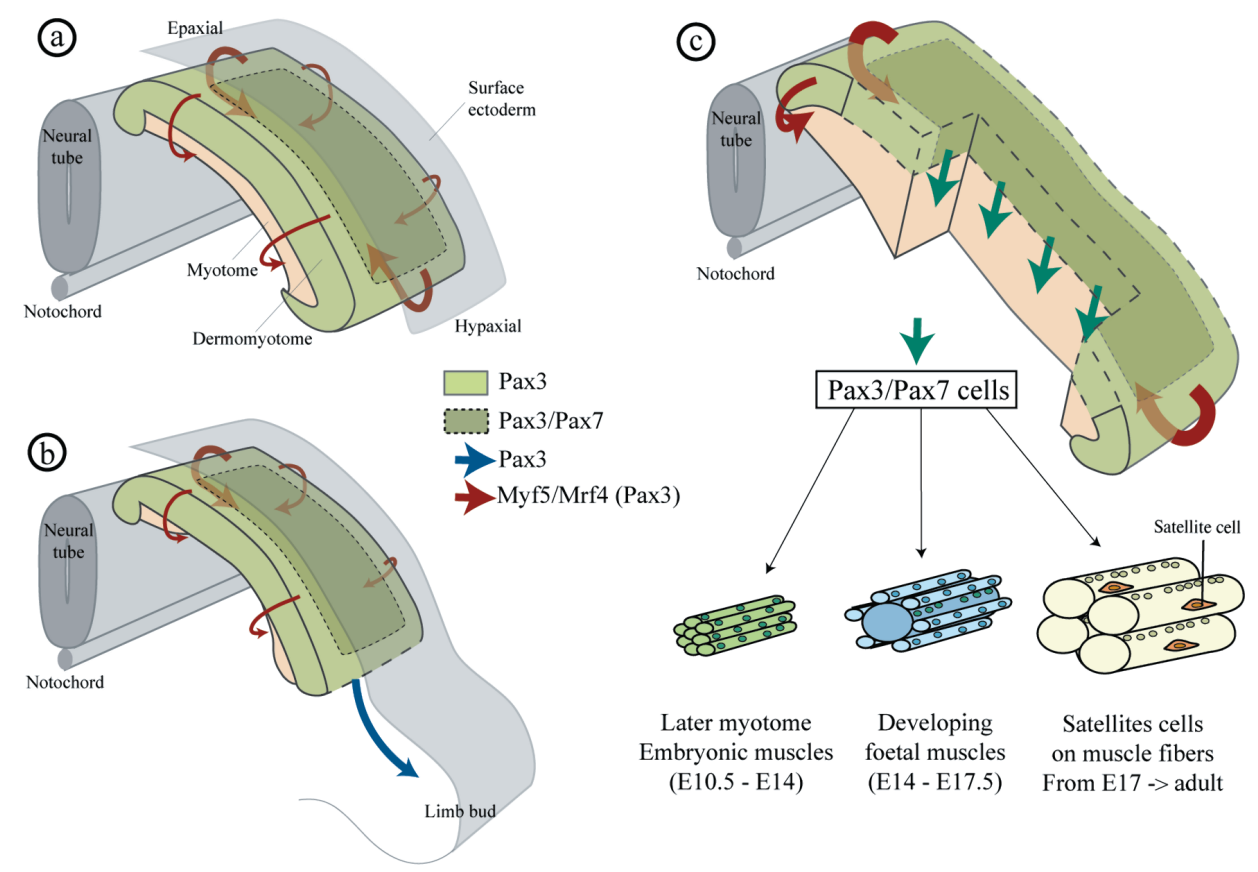

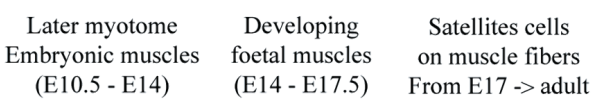

Figure 3. Successive waves of cells from the dermomyotome of the embryonic somite contribute to skeletal muscle formation. (a) Pax3positive cells that express the myogenic determination factors Myf5 and Mrf4 and, later, MyoD, delaminate from the edges of this epithelium to form the early myotomal muscle. (b) At the limb level, cells delaminate and migrate from the hypaxial (further from the axis) dermomyotome into the limb bud where the myogenic determination genes Myf5 and MyoD are subsequently activated. This migration is Pax3-dependent. (c) The central region of the dermomyotome, where both Pax3 and Pax7 are expressed, loses its epithelial structure so that Pax3/7-positive cells enter the underlying myotomal muscle. All subsequent muscle growth depends on this proliferating population of muscle stem cells. Before birth, these cells take up a satellite cell position under the basal lamina of the muscle fiber.

ing muscles in the mouse embryo, which either self-renew or differentiate (Fig. 4). Satellite cells that have activated myogenic determination genes either in vivo or after cell culture (Montarras et al. 2005) regenerate muscle much less efficiently, compared to the Pax-only satellite cells that also display more stem-cell-like properties, such as asymmetric cell division (Kuang et al. 2007).
The origin of satellite cells had been a subject of debate, but the recent identification of the dermomyotomal source of Pax3/7 stem cells for skeletal muscle development has led to the view that satellite cells are derived from this population. Pax3-Cre/Rosa26 experiments suggested that this is the case for muscles such as those of the hind limbs in which satellite cells do not express $\operatorname{Pax} 3$ (Schienda et

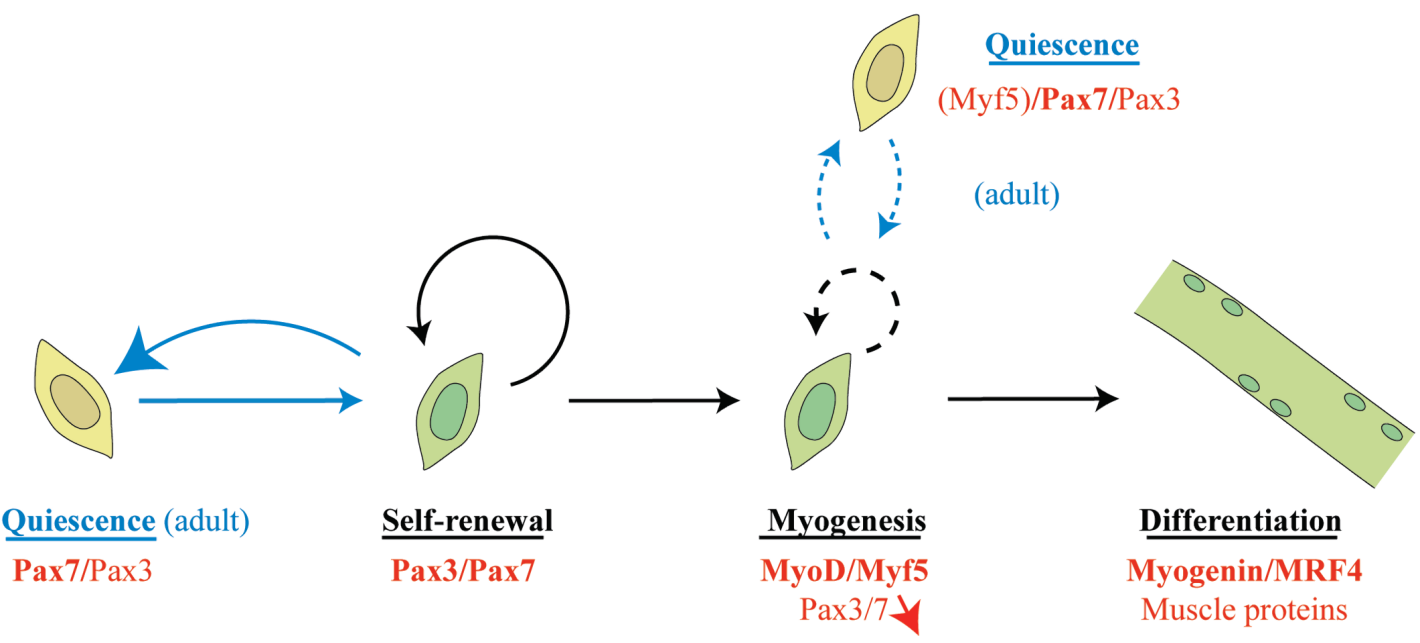

Figure 4. Skeletal muscle stem cell choices. In the embryo (black arrows), Pax3/Pax7-positive cells either self-renew or enter the myogenic program with activation of the myogenic determination genes $M y f 5$ and $M y o D$, accompanied by down-regulation of Pax3/7. In postnatal muscle, satellite cells participate in self-renewal and myogenesis, when activated in the context of postnatal growth and muscle repair, or remain quiescent (blue arrows) under the basal lamina of the muscle fiber. Many of these cells transcribe low levels of Myf5, indicating that they had already entered the myogenic program. 
al. 2006), and experimental manipulation of chick/quail chimeras has demonstrated that satellite cells come from the dermomyotome, from similar Pax3/7-positive cells to those in the mouse (Gros et al. 2005). More than $90 \%$ of all satellite cells at birth derive from this source. This does not preclude that other stem cells, such as the mesoangioblast cells present in the walls of blood vessels (Sampaolesi et al. 2003), may not also contribute, especially after injury.

\section{The Implications of Two Waves of Myogenesis}

In conclusion, there is therefore an early wave of myogenesis in which myogenic determination genes are directly activated by axial signals in the somite. This leads to the formation of an early differentiated muscle, the myotome. However, a second wave of myogenesis depends on Pax3/7-positive cells, also derived from the dermomyotome, that initially invade the muscle scaffold provided by the early myotome. These cells, unlike those of the first wave, self-renew as well as participate in myogenesis. They contribute the satellite cells of postnatal muscle, some of which have retained the stem cell properties of $\mathrm{Pax} 7^{+} / \mathrm{Myf5}^{-}$cells, whereas others $\left(\mathrm{Pax}^{+}, \mathrm{Myf5}^{+}\right)$ have at some stage engaged the myogenic program before reverting to a quiescent satellite cell state (Fig. 4). The evolutionary implications of the two waves of myogenesis are interesting. It is possible that the first constitutes a more primitive and static way of making segmented muscles following their somitic origin, whereas the second wave of Pax-dependent myogenesis leads to flexibility of muscle location and muscle growth, retaining myogenic stem cell potential also for regeneration in the adult.

\section{THE FUNCTION OF PAX3/7 IN SKELETAL MUSCLE STEM CELLS}

\section{Equivalence of Pax3 and Pax7}

A first question is whether Pax 3 and Pax 7 are equivalent. Their transcription profiles differ and, notably, Pax3 is more extensively expressed in the somite, whereas Pax 7 is restricted to the central domain of the dermomyotome. To address their relative function, we replaced the Pax3 gene with a Pax7-coding sequence and showed that, in homozygote $P a x 3^{\text {Pax7/Pax }}$ embryos, myogenesis in the trunk proceeds normally. However, in the limbs, this was not the case and muscle masses were deficient, notably distal muscles, with a more pronounced phenotype in the forelimbs. This deficit reflects reduced proliferation of Pax 7 progenitor cells and probably also migration defects. We therefore suggest that Pax 3 has acquired additional functions required for myogenesis in the limbs, at the time of tetrapod radiation, whereas functions in the trunk remain similar and probably reflect that of the ancestral Pax3/7 gene, present in the cephalochordate Amphioxus.

In postnatal satellite cells, the lack of Pax7 is not compensated by Pax 3 in those muscles in which the two Pax genes are coexpressed. It is not clear whether this reflects the level of Pax3. When Pax7 replaces Pax3, as mentioned above, $\operatorname{Pax} 3^{\operatorname{Pax} 7 / \operatorname{Pax} 7}$ phenotypes are milder than
$\operatorname{Pax} 3^{\operatorname{Pax} / 7}$, and this, together with other observations (Zhou et al. 2008), illustrates the dose sensitivity of Pax function, and indeed, Pax proteins in other systems demonstrate threshold effects (Buckingham and Relaix 2007). In satellite cells, manipulation of constructs expressing dominant-negative Pax3- or Pax7-Engrailed fusion proteins suggests that Pax 7 antiapoptotic targets are not affected by Pax3-Engrailed (Relaix et al. 2006). This is then different from the situation in the embryo, where Pax 3 and Pax 7 both have an antiapoptotic role (see next section).

\section{ROLE OF PAX3/7 IN MUSCLE STEM CELLS}

In most of the following discussion of the role of Pax3/7, they are considered equivalent, which is the case during the development of trunk musculature.

\section{Multipotency}

Maintenance of multipotency is an important issue in the Pax-positive cells of the dermomyotome of the somite. This epithelium, as its name implies, gives rise to the dermis of the back and to skeletal muscle, as well as endothelial and smooth muscle cells of some blood vessels (Fig. 5). Cell-labeling experiments in the chick (Kardon et al. 2002; Ben-Yair and Kalcheim 2005, 2008) have shown that a single cell can give rise to dermis/skeletal muscle,

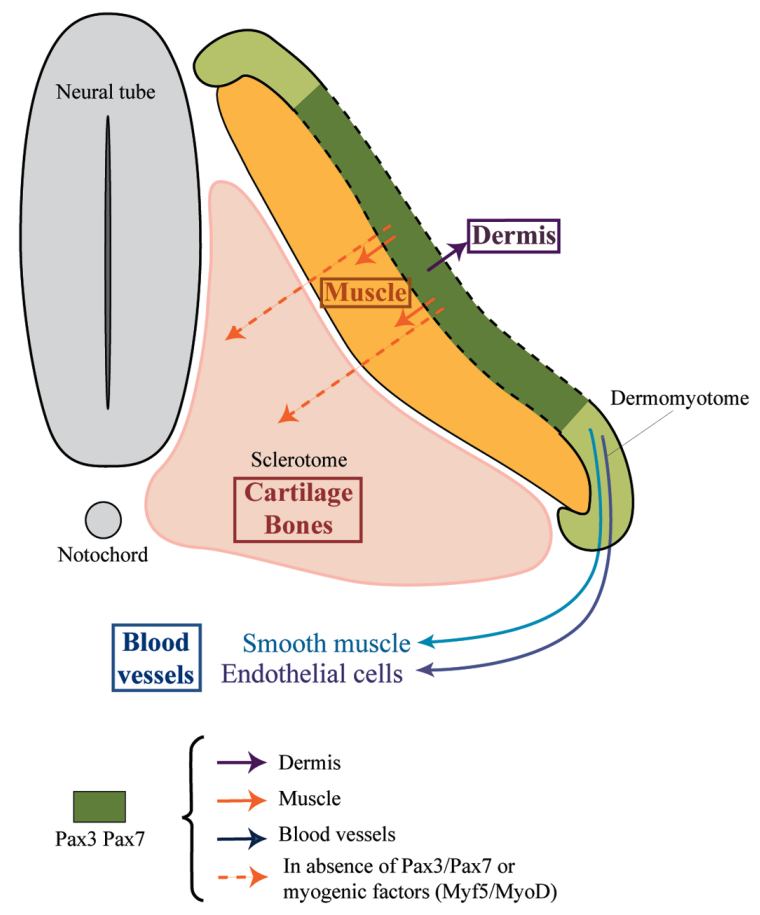

Figure 5. Pax-positive cells in the epithelial dermomyotome are multipotent, contributing to dermis and blood vessels as well as to skeletal muscle (arrows). In the absence of myogenic determination factors, cells that mislocate ventrally can adopt a cartilage/bone cell fate (dashed arrows). Normally, vertebrae and ribs are formed by Pax1/9-positive cells from the mesenchymal sclerotome compartment of the ventral somite. 
endothelial cells/skeletal muscle, and smooth muscle/skeletal muscle, and indeed it is probable that a multipotent Pax-positive cell gives rise to multiple derivatives. In the mouse embryo, retrospective clonal analysis and Pax3-GFP (green fluorescent protein) perdurance also demonstrates a common Pax progenitor for smooth muscle/skeletal muscle (Esner et al. 2006). As nonskeletal muscle derivatives form, $\mathrm{Pax} 3 / 7$ are down-regulated and their maintenance marks the skeletal muscle stem cell. In Pax3/7 double mutants, in the absence of myogenic determination factors, cells that would have formed skeletal muscle, depending on their environment, can also enter other differentiation pathways, such as that leading to bone and cartilage (Relaix et al. 2005; Tajbakhsh et al. 1996), which are derivatives of the ventral somite. Adipose tissue is also a default pathway when myogenic determination factors are absent (Rudnicki et al. 1993), and indeed, Pax7-positive satellite cells will form fat under some culture conditions (Shefer and Yablonka-Reuveni 2007).

It is not yet clear which Pax targets maintain multipotency. We have identified Foxc2 as a gene that is negatively regulated by $\operatorname{Pax} 3$ and have preliminary evidence that a Pax3/Foxc2-negative feedback loop may modulate cell-fate choices in the dermomyotome. We have also recently identified Dmrt2 as a Pax3 target in the dermomyotome. This gene, via its regulation of laminin, a ligand for integrin receptors, is probably involved in coordinating the structural integrity of the somite and the dermomyotome epithelium (Seo et al. 2006). This, of course, is critical for the reception of signals that will decide the subsequent fate of Pax3/7-positive cells. Integrins are also involved in the correct location of myogenic cells to the myotome, before differentiation (Bajanca et al. 2006).

\section{Migration}

Pax3, expressed at the borders of the dermomyotome, has an essential role in the delamination of cells from this epithelium, via its target c-met (Epstein et al. 1996; Relaix et al. 2003), which encodes a tyrosine kinase receptor required for this process, as well as for subsequent migration to more distant sites of myogenesis in response to its ligand hepatocyte growth factor (HGF) (Bladt et al. 1995). Pax3-regulated c-Met function thus determines the location of the Pax3/7 cells in the embryo and hence their exposure to signals that promote skeletal muscle formation. During muscle regeneration, migration of satellite cells to sites of injury is also important; it is not yet clear to what extent this depends on c-Met or cytokine receptors such as CXCR4, also involved in early migration of cells from the somites to the limbs (Vasyutina et al. 2005), and probably also genetically downstream from Pax3.

\section{Proliferation}

Pax3/7 probably promote proliferation, although targets have not yet been identified in this context. Indicative of this is the generation of rhabdomyosarcomas, with overactivation of Pax3/7 targets (see Relaix et al. 2003) by PAX3- or PAX7-FKHR, in which a chromosome translocation results in fusion of the PAX3/7 DNA-binding domain to the trans-activation domain of FKHR (FOXO1A). When Pax 7 replaces Pax3, progenitor cells in the embryonic limb do not proliferate as well (Relaix et al. 2004). Futhermore, it has been suggested that the deficit in satellite cells in the Pax 7 mutant mouse may be due to compromised proliferation (Oustanina et al. 2004); the cell cycle is perturbated in satellite cells that lack Pax7 (Relaix et al. 2006). Expression of Pax3 during proliferation of activated satellite cells may be important for their amplification (Conboy and Rando 2002). This is seen in Pax7-positive satellite cells from the limb, which do not normally express $\operatorname{Pax} 3$. However, in vivo injury of limb muscle of $\mathrm{Pax}^{\mathrm{GFP+}}$ mice did not result in detectable GFP (Montarras et al. 2005), as might be expected if Pax3 is expressed by all activated satellite cells. Conditional deletion of Pax3 postnatally (Pax3 mutant mice die prenatally because of neural crest defects) should clarify the issue of Pax3 function in satellite cells.

\section{Survival}

Pax3/7 have an important role in the survival of the muscle stem cell population. In Pax3 mutant embryos, apoptosis takes place in the hypaxial dermomyotome, where Pax7 is not expressed, and indeed in looking at the myogenic function of Pax3 in these cells, it was necessary to use heterozygote $\operatorname{Pax} 3^{\mathrm{Pax} 3-\mathrm{En} /+}$ mice, expressing a single allele encoding the dominant-negative Pax3-Engrailed protein, in which apoptosis is abrogated (Bajard et al. 2006). The Pax3/7-positive muscle stem cell population undergoes extensive apoptosis in the double-mutant mice, whereas this is not observed in the absence of $\operatorname{Pax} 3$ or $\operatorname{Pax} 7$ alone. Postnatally, the satellite cells of Pax 7 mutant mice undergo progressive cell death, and this antiapoptotic function of Pax7 is confirmed by the observation that introduction of a dominant-negative form of Pax7 (Pax7-Engrailed) into wild-type satellite cells leads to cell death (Relaix et al. 2006).

\section{Differentiation into Skeletal Muscle}

Pax3/7 expression maintains the myogenic potential of cells, and in the absence of these Pax factors, the myogenic determination genes $M y f 5$ and $M y o D$ are not activated. Myf5 and MyoD therefore lie genetically downstream from $P a x 3 / 7$. This is observed for the major Pax3/7 population of muscle stem cells present in all developing muscle masses (Relaix et al. 2005) and also at earlier stages in the hypaxial somite where, when Pax3 activity is attenuated, but the cells have not undergone apoptosis, Myf5 is not activated (Bajard et al. 2006).

Myf5 is regulated by a complex organization of cis-acting sequences more than $100 \mathrm{~kb} 5^{\prime}$ of the gene (Fig. 6). A sequence at $-57.5 \mathrm{~kb}$ directs expression of $M y f 5$ in the maturing hypaxial somite and limb buds, and deletion of this region in a bacterial artificial chromosome (BAC) containing the Mrf4-Myf5 locus had shown that it is essential for Myf5 activation (Hadchouel et al. 2003). We have shown by in vivo chromatin immunoprecipitation 


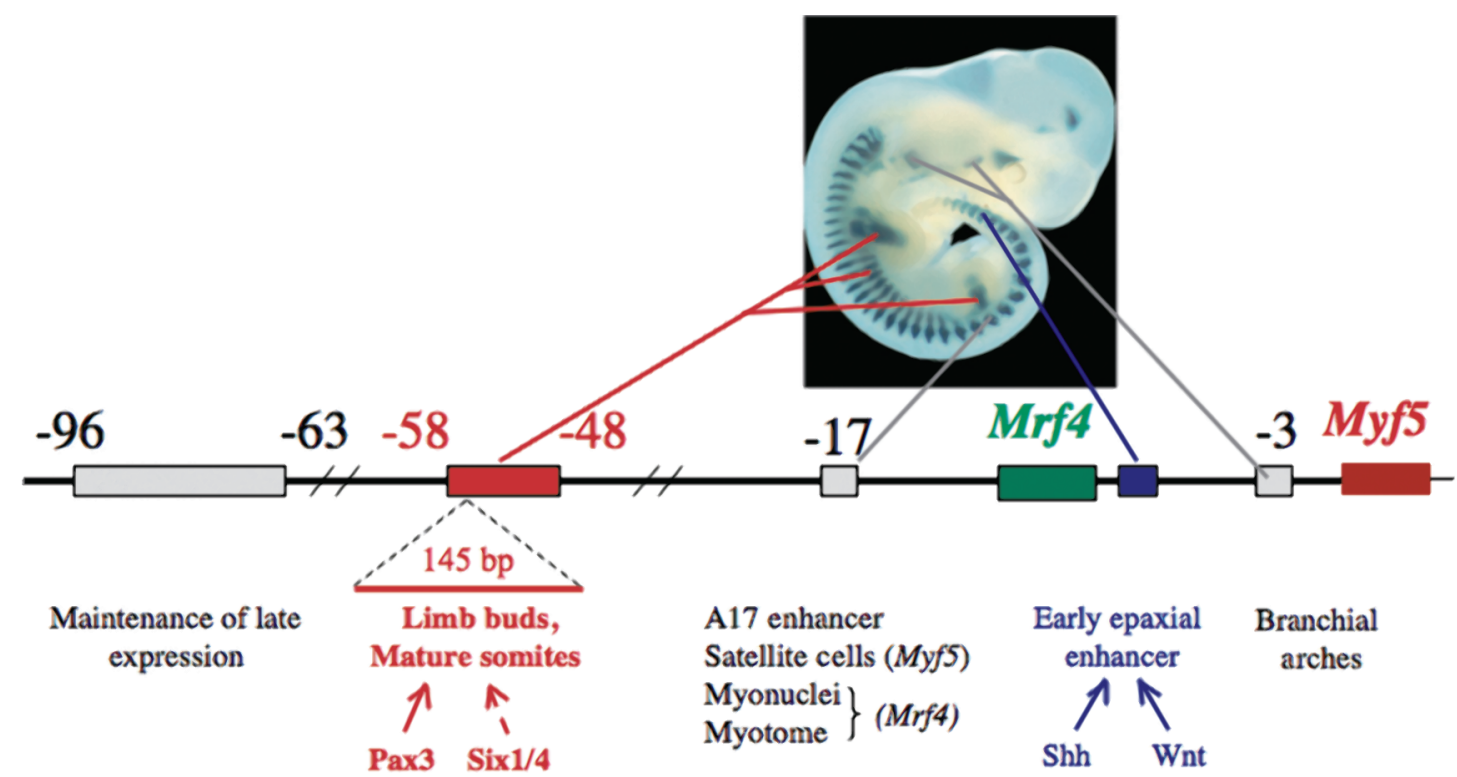

Figure 6. cis-regulatory elements of the Mrf4/Myf5 locus. The interaction between Mrf4 and Myf5 promoters with intragenic and $5^{\prime}$ regulatory elements is complex (see Carvajal et al. 2008). Myf5 activation during the first wave of myogenesis depends on an early epaxial enhancer, directly controlled by Wnt and Shh signaling. Most later embryonic expression depends on a region at $-58 /-48 \mathrm{~kb}$. Within this sequence, a 145-bp element alone directs expression in myogenic cells of mature somites and limb buds. This activity depends directly on Pax3 and is modulated by Six $1 / 4$.

(ChIP) analysis that Pax3 binds to a site in this sequence, which when mutated, abolishes all activity, leading us to conclude that $M y f 5$ is a direct target of Pax3 (Bajard et al. 2006). This therefore illustrates direct regulation of entry into the myogenic program by Pax3/7. It is not yet clear whether $M y o D$ is a direct Pax3/7 target; however, in the adult, as in the embryo, it lies genetically downstream from $P a x 3 / 7$. In many satellite cells, Myf5 is already activated and no longer dependent on Pax3/7, but this is not the case for MyoD. In Myf5 mutant satellite cells, expression of a dominant-negative form of Pax3/7 prevents $M y o D$ expression and subsequent myogenesis (Relaix et al. 2006).

Activation of myogenic determination genes not only depends on Pax3/7, but is also modulated by other factors. An example is provided by the Six homeodomain factors. Six $1 / 4$ are expressed at many sites of myogenesis, and notably, in the Pax3-positive cells of the hypaxial somite and limbs. The $-57.5-\mathrm{kb}$ Myf5 regulatory sequence that is Pax3-dependent contains a Six site, also occupied in vivo. Mutation of this site results in partial loss of expression in transgenic mice (Fig. 6) (Giordani et al. 2007). In keeping with this observation, mutation of Six 1/4 affects Myf5 activation (Grifone et al. 2005) and mutation of the genes encoding the Six cofactors Eya1/Eya2 also affects myogenesis (Grifone et al. 2007). It is notable that formation of the Drosophila eye depends not only on Eyeless and Twin of Eyeless (Pax), but also on Sine oculis (Six) and Eyes absent (Eya), acting in a regulatory cascade on downstream "eye" genes, thus illustrating the extent to which Pax gene regulatory networks are conserved across species and tissues (see Relaix and Buckingham 1999).

\section{MUSCLE STEM CELL SELF-RENEWAL VERSUS DIFFERENTIATION}

A major question in stem cell biology is how the balance between stem cell self-renewal versus differentiation is maintained. In the case of muscle stem cells, Pax3/7 activate myogenic determination genes leading to entry into the myogenic program. Other factors may also contribute to this step, such as Six 1/4, which is also present in the progenitor cells. To examine further how Pax3/7 modulates muscle stem cell behavior, we have performed screens based on different Pax3 alleles that we had engineered. They include a $\operatorname{Pax} 3^{G F P}$ allele, which permits purification of cells by flow cytometry (Montarras et al. 2005), and a $P a \times 3^{P A X 3-F K H R}$ allele, which leads to overactivation of Pax3 targets. This allele encodes the DNA-binding domain of Pax3 fused to the transcriptional activation domain of FKHR (FOXO1A). In $P a x 3^{P A X 3-F K H R /-}$ embryos, the Pax3 mutant phenotype is rescued, showing that Pax3 functions as a transcriptional activator in the myogenic context (Relaix et al. 2003). Comparative microarray analyses of cells from the limb buds or somites of $P a \times 3^{G F P /+}$ or Pax $3^{\text {GFP/PAX3-FKHR }}$ embryos led to the identification of potential Pax 3 targets that were then tested by in situ hybridization on gain-of-function $\left(\operatorname{Pax} 3^{P A X 3-F K H R /+}\right)$ (Relaix et al. 2003), partial loss-of-function $\left(\operatorname{Pax} 3^{\text {Pax3-En/+ }}\right.$ ) (Bajard et al. 2006), or loss-of-function $\left(\mathrm{Pax}^{--}\right)$embryos. 
Fgfr4 was identified as a gene lying genetically downtream from Pax3, and ChIP-chip analysis, using embryo extracts on a tiling array across this locus, led to the identification of a Pax3-binding region $3^{\prime}$ of the Fgfr4 gene. This 559-bp sequence directs reporter transgene expression at sites of myogenesis where Fgfr 4 is expressed. Mutation of the Pax3-binding sites abolished expression, and we therefore conclude that Fgfr4 is a direct Pax3 target. Other components of the FGF-signaling pathway also show genetic dependence on Pax3, notably Sprouty1, which was up-regulated in the microarray screen. Manipulation of Sprouty, using a conditional Sprouty-expressing transgenic line (Basson et al. 2008) crossed to $\mathrm{Pax} 3^{\mathrm{Cre} /+}$ mice (Engleka et al. 2005), permitted in vivo modulation of FGF signaling in Pax3-expressing cells and their progeny. In this experiment, the ratio between Pax3/7-positive stem cells and myogenin-positive differentiating muscle cells was perturbed in favor of the former. We therefore think that Pax3 orchestrates maintenance of stem cells versus entry into the myogenic program by regulation of FGF signaling (Fig. 7) (Lagha et al. 2008). Fgfr4 continues to be expressed in myogenic cells; E boxes, also present in the 3' regulatory sequence, are implicated in its regulation, and transgenic analysis suggests that myogenic factors maintain expression of this FGF receptor in differentiated muscle.

In adult satellite cells, Fgfr 4 is also expressed, and Fgfr 4 mutants have regeneration defects (Zhao et al. 2006). Sproutyl is present in quiescent satellite cells and is down-regulated in cultured satellite cells that have activated $M y o D$ and are progressing toward muscle differentiation (Fukada et al. 2007). Thus, Sprouty $1 /$ Fgfr4 modulation is also evident in postnatal muscle stem cells.

\section{CONCLUSIONS}

Pax3/7 orchestrate the entry of muscle stem cells into the myogenic program by direct activation of the myogenic determination gene $M y f 5$ and also by direct activation of the FGF receptor gene Fgfr 4 . Pax3 regulation of Sprouty1, which preliminary results suggest may also be direct, permits Pax3/7 control of the read-out of FGF signaling through this inhibitor. Sproutys affect tyrosine kinase receptor signaling in general so that Sprouty1 may also modulate signaling from other receptors such as PDGFR $\alpha$, also potentially implicated in myogenesis
(Crosby et al. 1998). The Notch signaling pathway also regulates muscle stem cell entry into the myogenic program, both postnatally for satellite cells (Conboy and Rando 2002) and in the embryo, where mutation of $R B P$ $J$ (Vasyutina et al. 2007) or Deltal (Schuster-Gossler et al. 2007) in Pax3/7-positive cells shifts them toward myogenesis, depleting the stem cell pool, with subsequent failure of muscle growth in the absence of Notch signaling. In keeping with this, interference with Notch signaling in the multipotent Pax3/7 cells of the dermomyotome promotes the muscle cell fate (Ben-Yair and Kalcheim 2008). Myostatin, a transforming growth factor- $\beta$ (TGF$\beta$ ) family member, and its inhibitor, follistatin, also affect the balance between self-renewal and myogenic differentiation, as shown by experimental manipulation in the chick embryo (Manceau et al. 2008). There is no evidence at present that $\mathrm{Pax} 3 / 7$ regulation intervenes in the Notch or Myostatin signaling pathways in muscle stem cells, and these therefore probably correspond to extrinsic controls of myogenic cell behavior.

Other genetic circuits linked to Pax $3 / 7$ also affect entry into the myogenic program. Six $1 / 4$ homeodomain proteins impact the Pax3-dependent Myf5 enhancer (Giordani et al. 2007), and E-box motifs, through which myogenic regulatory factors act, are probably responsible for the maintenance of transcription by the Pax3-dependent Fgfr4 enhancer (Lagha et al. 2008). These regulatory sequences provide examples of how Pax3/7-based genetic networks control skeletal myogenesis. Pax 3 targets are also beginning to emerge from our screens, shedding light on upstream regulation of multipotent stem cells in the dermomyotome. As mentioned briefly, Pax3/7 also regulate other aspects of muscle stem cell behavior: migration, through the gene encoding the c-Met tyrosine kinase receptor, and also proliferation and cell survival, through as yet unidentified Pax target genes.

These multiple functions of $\mathrm{Pax} 3 / 7$ in the myogenic context reflect those of other Pax factors that control stem cell populations required for tissue differentiation (see Fig. 2). It is evident that maintenance of multipotency and of self-renewal versus differentiation, together with correct positioning of stem cells, are critical for tissue formation in the embryo and regeneration in the adult. Furthermore, Pax function in cell survival, illustrated by $\mathrm{Pax} 3 / 7$ in the muscle context, is also observed in different

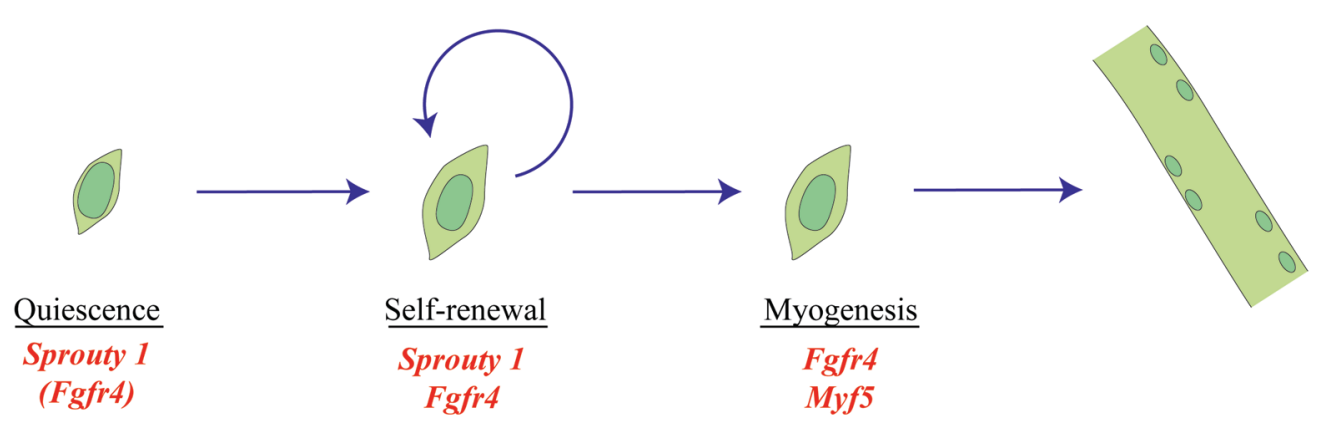

Figure 7. Stem cell choices are regulated by Pax3 target genes; Myf5 marks the entry of a cell into the myogenic program, also promoted by Fgfr4 signaling that is modulated by Sprouty1, expressed in Pax3/Pax7-positive muscle stem cells. 
stem cell contexts. It is no doubt important that genes required for the normal tissue cell fate of a cell should also regulate its survival. Loss of stem cell regulators, such as Pax3/7, results in a cell that is out of control and potentially dangerous for the organism.

\section{ACKNOWLEDGMENTS}

Work on skeletal muscle stem cells in M.B.'s laboratory is supported by the Pasteur Institute and the Centre National de la Recherche Scientifique (CNRS), with additional grants from the Association Française contre les Myopathies (AFM); the European Union, through the Integrated Project "EuroSyStem"; and the Networks of Excellence "Cells into Organs" and "MYORES." M.L. is supported by a fellowship from the AFM and T.S. from the "Cells into Organs" network.

\section{REFERENCES}

Bajanca, F., Luz, M., Raymond, K., Martins, G.G., Sonnenberg, A., Tajbakhsh, S., Buckingham, M., and Thorsteinsdottir, S. 2006. Integrin $\alpha 6 \beta 1$-laminin interactions regulate early myotome formation in the mouse embryo. Development 133: 1635-1644.

Bajard, L., Relaix, F., Lagha, M., Rocancourt, D., Daubas, P., and Buckingham, M.E. 2006. A novel genetic hierarchy functions during hypaxial myogenesis: Pax3 directly activates Myf5 in muscle progenitor cells in the limb. Genes Dev. 20: 2450-2464.

Basson, M.A., Echevarria, D., Petersen, Ahn, C., Sudarov, A., Joyner, A.L., Mason, I.J., Martinez, S., and Martin, G.R. 2008. Specific regions within the embryonic midbrain and cerebellum require different levels of FGF signaling during development. Development 135: 889-898.

Beauchamp, J.R., Heslop, L., Yu, D.S., Tajbakhsh, S., Kelly, R.G., Wernig, A., Buckingham, M.E., Partridge, T.A., and Zammit, P.S. 2000. Expression of CD34 and Myf5 defines the majority of quiescent adult skeletal muscle satellite cells. $J$. Cell Biol. 151: 1221-1234.

Ben-Yair, R. and Kalcheim, C. 2005. Lineage analysis of the avian dermomyotome sheet reveals the existence of single cells with both dermal and muscle progenitor fates. Development 132: 689-701.

Ben-Yair, R. and Kalcheim, C. 2008. Notch and bone morphogenetic protein differentially act on dermomyotome cells to generate endothelium, smooth, and striated muscle. J. Cell Biol. 180: 607-618.

Bladt, F., Riethmacher, D., Isenmann, S., Aguzzi, A., and Birchmeier, C. 1995. Essential role for the c-met receptor in the migration of myogenic precursor cells into the limb bud. Nature 376: 768-771.

Borello, U., Berarducci, B., Murphy, P., Bajard, L., Buffa, V., Piccolo, S., Buckingham, M., and Cossu, G. 2006. The Wnt/ $\beta$-catenin pathway regulates Gli-mediated Myf5 expression during somitogenesis. Development 133: 3723-3732.

Borycki, A.G., Li, J., Jin, F., Emerson, C.P., and Epstein, J.A. 1999. Pax3 functions in cell survival and in pax7 regulation. Development 126: 1665-1674.

Brunelli, S., Relaix, F., Baesso, S., Buckingham, M., and Cossu, G. 2007. $\beta$ Catenin-independent activation of MyoD in presomitic mesoderm requires PKC and depends on Pax3 transcriptional activity. Dev. Biol. 304: 604-614.

Buckingham, M. and Montarras, D. 2008. The origin and genetic regulation of myogenic cells: From the embryo to the adult. In Advances in muscle research: Skeletal muscle repair and regeneration (ed. S. Schiaffino and T. Partridge), vol. 3, pp. 19-44. Springer, Heidelberg.

Buckingham, M. and Relaix, F. 2007. The role of Pax genes in the development of tissues and organs: $\operatorname{Pax} 3$ and $\operatorname{Pax} 7$ regu- late muscle progenitor cell functions. Annu. Rev. Cell Dev. Biol. 23: 645-673.

Carvajal, J.J., Keith, A., and Rigby, P.W. 2008. Global transcriptional regulation of the locus encoding the skeletal muscle determination genes Mrf4 and Myf5. Genes Dev. 22: 265-276.

Conboy, I.M. and Rando, T.A. 2002. The regulation of notch signaling controls satellite cell activation and cell fate determination in postnatal myogenesis. Dev. Cell 3: 397-409.

Crosby, J.R., Seifert, R.A., Soriano, P., and Bowen-Pope, D.F. 1998. Chimaeric analysis reveals role of Pdgf receptors in all muscle lineages. Nat. Genet. 18: 385-388.

Engleka, K.A., Gitler, A.D., Zhang, M., Zhou, D.D., High, F.A., and Epstein, J.A. 2005. Insertion of Cre into the Pax3 locus creates a new allele of Splotch and identifies unexpected Pax3 derivatives. Dev. Biol. 280: 396-406.

Epstein, J.A., Shapiro, D.N., Cheng, J., Lam, P.Y., and Maas, R.L. 1996. Pax3 modulates expression of the c-Met receptor during limb muscle development. Proc. Natl. Acad. Sci. 93: 4213-4218.

Esner, M., Meilhac, S.M., Relaix, F., Nicolas, J.F., Cossu, G., and Buckingham, M.E. 2006. Smooth muscle of the dorsal aorta shares a common clonal origin with skeletal muscle of the myotome. Development 133: 737-749.

Fukada, S., Uezumi, A., Ikemoto, M., Masuda, S., Segawa, M., Tanimura, N., Yamamoto, H., Miyagoe-Suzuki, Y., and Takeda, S. 2007. Molecular signature of quiescent satellite cells in adult skeletal muscle. Stem Cells 25: 2448-2459.

Giordani, J., Bajard, L., Demignon, J., Daubas, P., Buckingham, M., and Maire, P. 2007. Six proteins regulate the activation of Myf5 expression in embryonic mouse limbs. Proc. Natl. Acad. Sci. 104: 11310-11315.

Grifone, R., Demignon, J., Houbron, C., Souil, E., Niro, C., Seller, M.J., Hamard, G., and Maire, P. 2005. Six1 and Six4 homeoproteins are required for Pax3 and Mrf expression during myogenesis in the mouse embryo. Development 132: 2235-2249.

Grifone, R., Demignon, J., Giordani, J., Niro, C., Souil, E., Bertin, F., Laclef, C., Xu, P.X., and Maire, P. 2007. Eya1 and Eya2 proteins are required for hypaxial somitic myogenesis in the mouse embryo. Dev. Biol. 302: 602-616.

Gros, J., Manceau, M., Thome, V., and Marcelle, C. 2005. A common somitic origin for embryonic muscle progenitors and satellite cells. Nature 435: 954-958.

Gustafsson, M.K., Pan, H., Pinney, D.F., Liu, Y., Lewandowski, A., Epstein, D.J., and Emerson, Jr., C. 2002. Myf5 is a direct target of long-range Shh signaling and Gli regulation for muscle specification. Genes Dev. 16: 114-126.

Hadchouel, J., Carvajal, J.J., Daubas, P., Bajard, L., Chang, T., Rocancourt, D., Cox, D., Summerbell, D., Tajbakhsh, S., Rigby, P.W., et al. 2003. Analysis of a key regulatory region upstream of the $M y f 5$ gene reveals multiple phases of myogenesis, orchestrated at each site by a combination of elements dispersed throughout the locus. Development 130: 3415-3426.

Kardon, G., Heanue, T.A., and Tabin, C.J. 2002. Pax3 and Dach 2 positive regulation in the developing somite. Dev. Dyn. 224: 350-355.

Kuang, S., Kuroda, K., Le Grand, F., and Rudnicki, M.A. 2007. Asymmetric self-renewal and commitment of satellite stem cells in muscle. Cell 129: 999-1010.

Lagha, M., Kormish, J.D., Rocancourt, D., Manceau, M., Epstein, J.A., Zaret, K.S., Relaix, F., and Buckingham, M.E. 2008. Pax3 regulation of FGF signaling affects the progression of embryonic progenitor cells into the myogenic program. Genes Dev. 22: 1828-1837.

Manceau, M., Gros, J., Savage, K., Thome, V., McPherron, A., Paterson, B., and Marcelle, C. 2008. Myostatin promotes the terminal differentiation of embryonic muscle progenitors. Genes Dev. 22: 668-681.

Montarras, D. and Buckingham, M. 2008. Isolation, characterisation and origin of muscle satellite cells. In Recent advances in skeletal myogenesis (ed. K. Tsuchida). Research Signpost Series, Trivandrum, Kerala, India. (In press.) 


\section{PAX3/7 ORCHESTRATION OF MUSCLE STEM CELL FATES}

Montarras, D., Morgan, J., Collins, C., Relaix, F., Zaffran, S., Cumano, A., Partridge, T., and Buckingham M. 2005. Direct isolation of satellite cells for skeletal muscle regeneration. Science 309: 2064-2067.

Oustanina, S., Hause, G., and Braun, T. 2004. Pax7 directs postnatal renewal and propagation of myogenic satellite cells but not their specification. EMBO J. 23: 3430-3439.

Relaix, F. and Buckingham, M. 1999. From insect eye to vertebrate muscle: Redeployment of a regulatory network. Genes Dev. 13: 3171-3178.

Relaix, F., Polimeni, M., Rocancourt, D., Ponzetto, C., Schafer, B.W., and Buckingham, M. 2003. The transcriptional activator PAX3-FKHR rescues the defects of Pax3 mutant mice but induces a myogenic gain-of-function phenotype with ligandindependent activation of Met signaling in vivo. Genes Dev. 17: 2950-2965.

Relaix, F., Rocancourt, D., Mansouri, A., and Buckingham, M. 2004. Divergent functions of murine Pax3 and Pax7 in limb muscle development. Genes Dev. 18: 1088-1105.

Relaix, F., Rocancourt, D., Mansouri, A., and Buckingham, M. 2005. A Pax3/Pax7-dependent population of skeletal muscle progenitor cells. Nature 435: 948-953.

Relaix, F., Montarras, D., Zaffran, S., Gayraud-Morel, B., Rocancourt, D., Tajbakhsh, S., Mansouri, A., Cumano, A., and Buckingham, M. 2006. Pax3 and Pax7 have distinct and overlapping functions in adult muscle progenitor cells. J. Cell Biol. 172: 91-102.

Rudnicki, M.A., Schnegelsberg, P.N., Stead, R.H., Braun, T., Arnold, H.H., and Jaenisch, R. 1993. MyoD or Myf-5 is required for the formation of skeletal muscle. Cell 75: $1351-1359$.

Sampaolesi, M., Torrente, Y., Innocenzi, A., Tonlorenzi, R., D’Antona, G., Pellegrino, M.A., Barresi, R., Bresolin, N., De Angelis, M.G., Campbell, K.P., et al. 2003. Cell therapy of $\alpha$ sarcoglycan null dystrophic mice through intra-arterial delivery of mesoangioblasts. Science 301: 487-492.

Schienda, J., Engleka, K.A., Jun, S., Hansen, M.S., Epstein, J.A., Tabin, C.J., Kunkel, L.M., and Kardon, G. 2006. Somitic origin of limb muscle satellite and side population cells. Proc. Natl. Acad. Sci. 103: 945-950.
Schuster-Gossler, K., Cordes, R., and Gossler, A. 2007. Premature myogenic differentiation and depletion of progenitor cells cause severe muscle hypotrophy in Deltal mutants. Proc. Natl. Acad. Sci. 104: 537-542.

Seo, K.W., Wang, Y., Kokubo, H., Kettlewell, J.R., Zarkower, D.A., and Johnson, R.L. 2006. Targeted disruption of the DM domain containing transcription factor Dmrt2 reveals an essential role in somite patterning. Dev. Biol. 290: 200-210.

Shefer, G. and Yablonka-Reuveni, Z. 2007. Reflections on lineage potential of skeletal muscle satellite cells: Do they sometimes go MAD? Crit. Rev. Eukaryot. Gene Expr. 17: 13-29.

Tajbakhsh, S., Rocancourt, D., and Buckingham, M. 1996. Muscle progenitor cells failing to respond to positional cues adopt non-myogenic fates in myf-5 null mice. Nature 384: 266-270.

Tajbakhsh, S., Borello, U., Vivarelli, E., Kelly, R., Papkoff, J., Duprez, D., Buckingham, M., and Cossu, G. 1998. Differential activation of $M y f 5$ and $M y o D$ by different Wnts in explants of mouse paraxial mesoderm and the later activation of myogenesis in the absence of Myf5. Development 125: 4155-4162.

Teboul, L., Summerbell, D., and Rigby, P.W. 2003. The initial somitic phase of Myf5 expression requires neither Shh signaling nor Gli regulation. Genes Dev. 17: 2870-2874.

Vasyutina, E., Stebler, J., Brand-Saberi, B., Schulz, S., Raz, E., and Birchmeier, C. 2005. CXCR4 and Gabl cooperate to control the development of migrating muscle progenitor cells. Genes Dev. 19: 2187-2198.

Vasyutina, E., Lenhard, D.C., Wende, H., Erdmann, B., Epstein, J.A., and Birchmeier, C. 2007. RBP-J (Rbpsuh) is essential to maintain muscle progenitor cells and to generate satellite cells. Proc. Natl. Acad. Sci. 104: 4443-4448.

Zhao, P., Caretti, G., Mitchell, S., McKeehan, W.L., Boskey, A.L., Pachman, L.M., Sartorelli, V., and Hoffman, E.P. 2006. Fgfr4 is required for effective muscle regeneration in vivo. Delineation of a MyoD-Tead2-Fgfr4 transcriptional pathway. J. Biol. Chem. 281: 429-438.

Zhou, H.M., Wang, J., Rogers, R., and Conway, S.J. 2008. Lineage-specific responses to reduced embryonic Pax3 expression levels. Dev. Biol. 315: 369-382. 


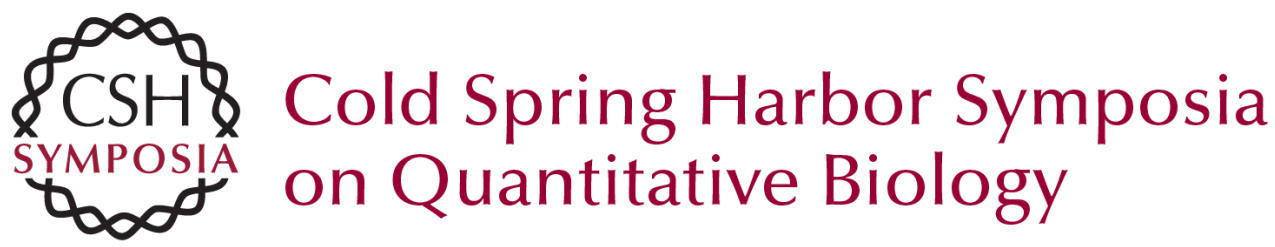

\section{Regulation of Skeletal Muscle Stem Cell Behavior by Pax3 and Pax7}

M. Lagha, T. Sato, L. Bajard, et al.

Cold Spring Harb Symp Quant Biol 2008 73: 307-315 originally published online November 6, 2008 Access the most recent version at doi:10.1101/sqb.2008.73.006

References This article cites 49 articles, 31 of which can be accessed free at: http://symposium.cshlp.org/content/73/307.full.html\#ref-list-1

\section{License}

Email Alerting Receive free email alerts when new articles cite this article - sign up in the Service box at the top right corner of the article or click here. 